\title{
Simultaneous determination of new psychoactive substances and illicit drugs in sewage: Potential of micro-liquid chromatography tandem mass spectrometry in wastewater-based epidemiology
}

\author{
Alberto Celma ${ }^{\text {, }}$, Juan V. Sancho ${ }^{\mathrm{a}}$, Noelia Salgueiro-González ${ }^{\mathrm{b}}$, Sara Castiglioni ${ }^{\mathrm{b}}$, \\ Ettore Zuccato ${ }^{\mathrm{b}}$, Félix Hernández ${ }^{\mathrm{a}}$, Lubertus Bijlsma ${ }^{\mathrm{a}, *}$ \\ a Research Institute for Pesticides and Water, University Jaume I, Avda. Sos Baynat S/N, E-12071 Castelló, Spain \\ ${ }^{\mathrm{b}}$ Istituto di Ricerche Farmacologiche Mario Negri - IRCCS, Department of Environmental Health Science, Via La Masa 19, I-20156 Milan, Italy
}

\section{A R T I C L E I N F O}

\section{Article history:}

Received 5 March 2019

Received in revised form 20 May 2019

Accepted 26 May 2019

Available online $\mathrm{xxx}$

\section{Keywords:}

Capillary liquid chromatography

New psychoactive substances

Wastewater analysis

Drugs of abuse

Tandem mass spectrometry

IonKey

\begin{abstract}
A B S T R A C T
Wastewater-based epidemiology (WBE) can give valuable light on the extent and actual use of new psychoactive substances (NPS). In this work, a fully validated methodology for the simultaneous determination of illicit drugs and NPS in wastewater by solid-phase extraction followed by UHPLC-MS/MS has been developed. The small sample volume $(5 \mathrm{~mL})$ required for analysis is of high interest, especially when performing large sampling campaigns involving many locations of different geographical origin, as it has been performed in the past. The method was applied to wastewater samples from different European locations and permitted the simultaneous monitoring of conventional drugs and NPS. Cocaine, amphetamine, MDMA, methamphetamine and ketamine were found in all wastewater samples, and several NPS (dipentylone, butylone, mephedrone, methedrone and methylone) were observed in some of the samples monitored. It is noteworthy that dipentylone was detected in wastewater for the very first time. Furthermore, a detailed comparison of micro liquid chromatography $(\mu L C)$ and UHPLC, both coupled to tandem mass spectrometry, in terms of sensitivity and reproducibility has been made for the first time in the application field of WBE. An average increase factor of 14 (mass normalized data) was observed in sensitivity for $\mu \mathrm{LC}-\mathrm{MS} / \mathrm{MS}$. The overall method performance was also compared (un-normalized data), and an average increase sensitivity factor of 4.5 was observed for $\mu$ LC-MS/MS. However, large deviations in retention time (up to $0.4 \mathrm{~min}$ ) affected the reproducibility and robustness of the $\mu \mathrm{LC}-\mathrm{MS} / \mathrm{MS}$ method when it was applied to wastewater analysis. Although in this work $\mu L C-M S / M S$ was strongly influenced by the amount of matrix loaded in the separation device, its enhanced sensitivity and promotion of green chemistry (faster analysis time and less solvent consumption) allow to expect improved future applications, especially when analytes are present at very low concentrations.
\end{abstract}

(C) 2019 Elsevier B.V. All rights reserved.

\section{Introduction}

The European Monitoring Centre for Drugs and Drug Addiction (EMCDDA) has recorded more than 670 new psychoactive substances (NPS) comprising mainly synthetic cathinones, synthetic cannabinoids and phenethylamines [1]. The easiness on modifying the chemical structure of a psychoactive substance to produce a new one to avoid regulation and maintain clandestinity has contributed to the development of such large number of available NPS [2]. Therefore, the identification and quantification of NPS in differ-

\footnotetext{
* Corresponding author.

E-mail address: bijlsma@uji.es (L. Bijlsma).
}

ent matrices of interest is a high-demanding analytical challenge $[3,4]$.

Several approaches have been reported for the determination of NPS through the analysis of urine, post-mortem fluids, hair, wastewater (WW) or seized products [5-11]. WW seems a suitable matrix for the determination of NPS since it provides an overview of what is being consumed in a whole community. Consumed drugs are excreted as either parent compound or metabolites and end up in the sewage system, finally entering the wastewater treatment plants (WWTPs). By collecting a representative sample of influent WW, a huge anonymous urine test of a certain community can be obtained. Some analytical approaches use high resolution mass spectrometry (HRMS) for the analysis of NPS in WW [7,10-14] based on the strong identification potential of this technique. How- 
ever, the sensitivity cannot be sufficient to detect and identify these compounds present at very low concentration levels in these complex matrices [13]. LC coupled to tandem mass spectrometry (UHPLC-MS/MS) with triple quadrupole (QqQ) appears as one of the most convenient tools to this aim, as it allows to quantify very low analyte concentrations. This technique has been in fact applied for the determination of some NPS in WW, albeit only a small amount of NPS have been detected $[5-7,15]$.

Recently developed micro fluidic chromatographic techniques, such as micro-liquid chromatography ( $\mu \mathrm{LC}$ ) coupled to tandem mass spectrometry ( $\mu$ LC-MS/MS) allow to reach limits of detection and quantification lower than conventional UHPLC-MS/MS [16]. Reduction of internal diameter of the chromatographic column and

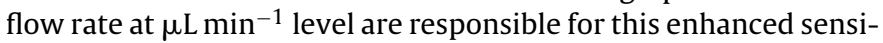
tivity $[17,18]$. By the utilization of low flow rates $\left(<100 \mu \mathrm{L} \mathrm{min}^{-1}\right)$ the ionization efficiency is higher. In addition, electrospray plume reduces in size and, therefore, sampling efficiency in the electrospray source is greatly improved [19]. Since low volumes are involved in this equipment, special attention needs to be paid to dead volumes in connections and injection valve. Newly developed integrated $\mu$ LC-ESI chip MS interfaces greatly reduce the problems related to dead volumes in laboratory-assembled $\mu$ LC equipment $[17,18,20]$. Short analysis time, lower mobile phase consumption, higher sensitivity, lower sample volume and easy coupling to mass spectrometry are some of the main advantages of $\mu \operatorname{LC}[18,20]$. Therefore, $\mu \mathrm{LC}$ may be a valuable technique for the development of green analytical methodologies because of the reduced usage of organic solvents and reduced sample volume. However, analysis time is often larger than in convention UHPLC and, due to the smaller dimensions, sample composition may compromise the $\mu \mathrm{LC}$ separations $[16,18]$. These two aspects are relevant drawbacks that need to be fully addressed during method optimization and sample analysis.

$\mu L C-M S / M S$ has been applied in food [18,21], urine [17,22], plasma [23,24], serum [16] and blood [25] matrices for the determination of pharmaceuticals $[16,17,22,24,25]$, pesticides, toxins and organic contaminants [18], polyphenols [21] and proteins [23]. However, we have not found previous applications of $\mu$ LC-MS/MS to the analysis of NPS and illicit drugs (ID) in WW matrices.

In this work, a sensitive method for the simultaneous determination of 22 compounds, including NPS, ID and some main metabolites, by means of UHPLC-MS/MS (QqQ) has been developed and validated. The methodology applied minimizes the amount of sample necessary for analysis allowing to simplify sampling and delivering expenses, which is of relevance in large campaigns involving several WWTPs from different geographical locations. The NPS included in the method were selected based on their possible use as a replacement of conventional recreational ID, and are among those mostly reported. In addition, the potential application of micro-liquid chromatography for the determination of NPS in WW has been evaluated, with a detailed discussion of the advantages and drawbacks of this approach. A thoroughly comparison of $\mu L C-M S / M S$ and UHPLC-MS/MS has been made in terms of sensitivity and method reproducibility. This is, to the best of our knowledge, the first contribution where the potential of $\mu \mathrm{LC}$ MS/MS has been evaluated for the monitoring of ID and NPS in WW.

\section{Experimental}

\subsection{Chemicals and materials}

In total, 22 ID, NPS and main metabolites were included in this study. Further details about the chemicals and materials used in this study can be consulted in Supporting Information.

\subsection{Sample treatment}

Before being extracted by solid-phase extraction (SPE), raw WW was centrifuged at $6000 \mathrm{rpm}$ for $5 \mathrm{~min}$. Then, $5 \mathrm{~mL}$ aliquot was spiked with $40 \mu \mathrm{L}$ of $50 \mu \mathrm{g} \mathrm{L}^{-1}$ solution of isotope-labelled internal standards (ILIS), resulting in concentration of $400 \mathrm{ng} \mathrm{L}^{-1}$ in raw WW. After conditioning SPE cartridges with $2 \times 3 \mathrm{~mL}$ of $\mathrm{MeOH}$ and $2 \times 3 \mathrm{~mL}$ of $\mathrm{H}_{2} \mathrm{O}$,WW samples were extracted by means of Oasis HLB $\left(60 \mathrm{mg}, 3 \mathrm{~cm}^{3}\right.$ ) SPE cartridges. After loading the sample, cartridges were rinsed with $50 \mathrm{~mL}$ of Milli-Q water to reduce the amount of matrix interferences extracted in the SPE. The retained compounds were eluted with $1 \mathrm{~mL}$ of $\mathrm{MeOH}$ that was then evaporated at $40^{\circ} \mathrm{C}$ under vacuum conditions for around $90 \mathrm{~min}$ in a miVac DUO Concentrator (Genevac, Italy). Extracts were reconstituted with $200 \mu \mathrm{L}$ of $\mathrm{H}_{2} \mathrm{O}: \mathrm{MeOH}(90: 10)$ and filtered through $0.22 \mu \mathrm{m} \times 4 \mathrm{~mm}$ nylon filters (Membrane Solutions, Plano, TX, USA). With this procedure, the preconcentration factor was 25 . Finally, $3 \mu \mathrm{L}$ of filtered extract was injected in the UHPLC-MS/MS system. Evaluation and optimization of SPE, centrifugation and evaporation steps can be found in Supporting Information. A summary of the sample procedure is presented in Fig. S1.

\subsection{Instrumentation}

\subsubsection{UHPLC-MS/MS analysis}

UHPLC-MS/MS sample analysis was performed using a Waters Acquity H-class UPLC system (Waters Corporation, MA, USA) coupled to a triple quadrupole mass spectrometer (Xevo TQS, Waters Micromass, Manchester, UK) equipped with an electrospray ionization source (ESI) operated in positive ionization mode. Chromatographic separation was performed by means of an Acquity UPLC BEH $C_{18}$ column $(1.7 \mu \mathrm{m}, 50 \times 2.1 \mathrm{~mm})$ from Waters at a flow rate of $300 \mu \mathrm{min}^{-1}$. Column temperature was kept at $40^{\circ} \mathrm{C}$ and sample manager was kept at $7^{\circ} \mathrm{C}$. Elution was performed with gradient of $\mathrm{A}: \mathrm{H}_{2} \mathrm{O} 0.01 \% \mathrm{HCOOH}$ and $\mathrm{B}$ : $\mathrm{MeOH} 0.01 \% \mathrm{HCOOH}$, as follows: 0 min $10 \%$ B, 2 min $60 \%$ B, $2.50 \min 90 \%$ B, $3.50 \min 90 \%$ B, $3.60 \mathrm{~min} 10 \% \mathrm{~B}$ until $5.50 \mathrm{~min}$ for re-equilibrating the column for the next injection. Cone and desolvation gas were dry nitrogen set to $250 \mathrm{Lh}^{-1}$ and $1200 \mathrm{Lh}^{-1}$, respectively. For the operation of MS/MS mode, collision gas was argon 99.995\% (Praxair, Madrid, Spain) set to $0.15 \mathrm{~mL} \mathrm{~min}^{-1}$. Source temperature was kept at $120^{\circ} \mathrm{C}$ and capillary voltage was established at $3.0 \mathrm{kV}$. All data was acquired and processed using MassLynx v4.1 software (Waters, Manchester, UK).

\subsection{2. $\mu L C-M S / M S$ analysis}

Sample analysis was performed using a Waters Acquity M-class UPLC system (Waters Corporation, MA, USA), equipped with a Peptide $\mathrm{BEH} \mathrm{C}_{18} 130 \AA 1.7 \mu \mathrm{m} 150 \mu \mathrm{m} \times 50 \mathrm{~mm}$ ionKey LC separation device (Waters Corporation) and interfaced to a triple quadrupole mass spectrometer (Xevo TQS, Waters Micromass, Manchester, UK) operated in positive ionization mode. iKey device was kept at $40^{\circ} \mathrm{C}$ and sample manager was kept at $7^{\circ} \mathrm{C}$. Chromatographic separation was performed with gradient of $\mathrm{A}: \mathrm{H}_{2} \mathrm{O} 0.01 \% \mathrm{HCOOH}$ and B: $\mathrm{MeOH} 0.01 \% \mathrm{HCOOH}$, as follows: 0 min $30 \% \mathrm{~B}, 2 \mathrm{~min} 60 \% \mathrm{~B}$, $2.10 \mathrm{~min} 90 \% \mathrm{~B}, 3.10 \mathrm{~min} 90 \% \mathrm{~B}, 3.20 \mathrm{~min} 30 \% \mathrm{~B}$ until $5.50 \mathrm{~min}$ for re-equilibrating the column for next injection. Flow rate was established at $3 \mu \mathrm{L} \mathrm{min}^{-1}$. Cone and nebulizer gas were dry nitrogen set to $250 \mathrm{~L} \mathrm{~h}^{-1}$ and $7 \mathrm{bar}$, respectively. For the operation of MS/MS mode, collision gas was argon 99.995\% (Praxair, Madrid, Spain) set to $0.15 \mathrm{~mL} \mathrm{~min}{ }^{-1}$. Source temperature was kept at $120^{\circ} \mathrm{C}$ and capillary voltage was established at $3.5 \mathrm{kV}$. All data was acquired and processed using MassLynx v4.1 software (Waters, Manchester, UK). 
Table 1

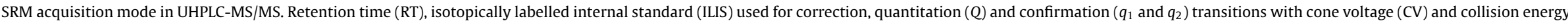
(CE) associated.

\begin{tabular}{|c|c|c|c|c|c|c|c|c|c|c|c|c|}
\hline \multirow{2}{*}{ Compound } & \multirow{2}{*}{$\mathrm{RT}(\min )$} & \multirow{2}{*}{ ILIS } & \multirow{2}{*}{ Precursor ion } & \multirow{2}{*}{$\mathrm{CV}(\mathrm{V})$} & \multicolumn{2}{|l|}{$Q$ transition } & \multicolumn{2}{|l|}{$q_{1}$ transition } & \multicolumn{2}{|l|}{$q_{2}$ transition } & \multirow{2}{*}{$\mathrm{Q} / q_{1}(\mathrm{RSD} \%)$} & \multirow{2}{*}{$\mathrm{Q} / q_{2}(\mathrm{RSD} \%)$} \\
\hline & & & & & Product ion & $\mathrm{CE}(\mathrm{eV})$ & Product ion & $\mathrm{CE}(\mathrm{eV})$ & Product ion & $\mathrm{CE}(\mathrm{eV})$ & & \\
\hline Amphetamine $^{\mathrm{a}}$ & 2.45 & Amphetamine- $d_{6}$ & 136.1 & 10 & 119.0 & 10 & 91.1 & 20 & 65.0 & 40 & $0.8(7)$ & $44.5(20)$ \\
\hline Benzoylecgonine ${ }^{\mathrm{b}}$ & 2.81 & Benzoylecgonine- $d_{3}$ & 290.1 & 40 & 168.1 & 20 & 105.2 & 30 & 77.0 & 50 & $3.0(4)$ & $8.9(5)$ \\
\hline Butylone & 2.73 & Butylone- $d_{3}$ & 222.1 & 30 & 174.0 & 20 & 146.1 & 20 & 131.1 & 30 & $2.2(9)$ & $4.0(7)$ \\
\hline Cocaine $^{\mathrm{a}}$ & 3.13 & Cocaine- $d_{3}$ & 304.2 & 40 & 182.2 & 20 & 82.0 & 30 & 77.0 & 50 & $2.9(5)$ & $15.5(8)$ \\
\hline Dimethylone & 2.35 & Methylone- $d_{3}$ & 222.1 & 40 & 147.0 & 20 & 72.1 & 20 & 91.0 & 30 & $0.8(4)$ & $2.7(6)$ \\
\hline Dipentylone & 3.19 & $\alpha-\mathrm{PVP}-d_{8}$ & 350.1 & 30 & 100.1 & 20 & 135.0 & 20 & 175.2 & 20 & $1.8(4)$ & $1.9(7)$ \\
\hline Ketamine & 2.97 & Ketamine- $d_{4}$ & 238.2 & 50 & 125.0 & 30 & 179.1 & 20 & 220.1 & 20 & $2.1(12)$ & $4.0(7)$ \\
\hline MDMA $^{a}$ & 2.57 & MDMA- $d_{5}$ & 194.1 & 10 & 163.0 & 10 & 135.0 & 20 & 105.1 & 20 & $2.7(6)$ & $3.3(6)$ \\
\hline MDPV & 3.24 & MDPV- $d_{8}$ & 276.1 & 35 & 126.0 & 30 & 175.1 & 20 & 149.0 & 30 & $2.0(4)$ & $1.3(7)$ \\
\hline Mephedrone & 2.83 & Mephedrone- $d_{3}$ & 178.1 & 40 & 145.0 & 20 & 160.1 & 10 & 91.1 & 30 & $0.6(6)$ & $237(13)$ \\
\hline Methamphetamine ${ }^{\mathrm{a}}$ & 2.55 & Methamphetamine- $d_{5}$ & 150.2 & 10 & 119.3 & 10 & 91.0 & 20 & 65.0 & 40 & $0.4(5)$ & $19.4(10)$ \\
\hline Methedrone & 2.57 & MDMA- $d_{5}$ & 194.1 & 40 & 161.3 & 20 & 176.1 & 10 & 146.1 & 30 & $0.9(11)$ & $3.4(9)$ \\
\hline Methoxetamine & 3.11 & Methoxetamine- $d_{3}$ & 248.2 & 50 & 121.1 & 30 & 175.0 & 20 & 203.0 & 10 & $1.0(11)$ & $0.7(5)$ \\
\hline Methylone & 2.24 & Methylone- $d_{3}$ & 208.1 & 30 & 160.0 & 20 & 132.0 & 30 & 91.1 & 40 & $2.8(6)$ & $17.6(11)$ \\
\hline N-ethcathinone & 2.35 & Methylone- $d_{3}$ & 178.1 & 20 & 117.1 & 10 & 130.0 & 30 & 160.1 & 10 & $0.6(3)$ & $0.1(6)$ \\
\hline PMMA & 2.70 & PMMA- $d_{3}$ & 180.1 & 40 & 149.0 & 10 & 121.1 & 20 & 91.1 & 30 & $1.2(2)$ & $9.5(9)$ \\
\hline$\alpha-\mathrm{PVP}$ & 3.19 & $\alpha-\mathrm{PVP}-d_{8}$ & 232.2 & 10 & 105.1 & 30 & 91.0 & 20 & 126.0 & 20 & $0.2(7)$ & $0.6(5)$ \\
\hline 3,4-DiMeO- $\alpha$-PVP & 3.18 & Methoxetamine- $d_{3}$ & 292.1 & 30 & 221.1 & 20 & 151.1 & 30 & 126.0 & 30 & $1.0(9)$ & $1.8(10)$ \\
\hline 4-chloro- $\alpha$-PPP & 3.16 & Methoxetamine- $d_{3}$ & 238.1 & 50 & 139.0 & 20 & 98.0 & 30 & 103.0 & 30 & $1.9(5)$ & $4.0(7)$ \\
\hline 4-FMC & 2.28 & MDMA- $d_{5}$ & 182.0 & 30 & 149.0 & 20 & 103.1 & 30 & 164.0 & 10 & $7.4(4)$ & $0.8(3)$ \\
\hline 4-MEC & 2.98 & Mephedrone- $d_{3}$ & 192.1 & 50 & 145.0 & 20 & 174.1 & 10 & 91.0 & 30 & $0.6(2)$ & $4.7(4)$ \\
\hline 4-МеРРP & 3.03 & Mephedrone- $d_{3}$ & 218.1 & 35 & 119.0 & 20 & 98.3 & 30 & 147.2 & 20 & $2.2(2)$ & $187(12)$ \\
\hline Amphetamine- $d_{6}$ & 2.45 & - & 142.2 & 10 & 93.0 & 20 & - & - & - & - & - & - \\
\hline Benzoylecgonine- $d_{3}$ & 2.81 & - & 293.3 & 40 & 171.1 & 20 & - & - & - & - & - & - \\
\hline Butylone- $d_{3}$ & 2.73 & - & 225.1 & 30 & 177.1 & 20 & - & - & - & - & - & - \\
\hline Cocaine- $d_{3}$ & 3.13 & - & 307.3 & 40 & 185.2 & 20 & - & - & - & - & - & - \\
\hline Ketamine- $d_{4}$ & 2.97 & - & 242.2 & 50 & 129.2 & 30 & - & - & - & - & - & - \\
\hline MDMA- $d_{5}$ & 2.57 & - & 199.1 & 10 & 165.1 & 10 & - & - & - & - & - & - \\
\hline MDPV- $d_{8}$ & 3.24 & - & 184.2 & 35 & 205.0 & 30 & - & - & - & - & - & - \\
\hline Mephedrone- $d_{3}$ & 2.83 & - & 181.1 & 40 & 145.1 & 20 & - & - & - & - & - & - \\
\hline Methamphetamine- $d_{5}$ & 2.55 & - & 155.2 & 10 & 92.1 & 20 & - & - & - & - & - & - \\
\hline Methoxetamine- $d_{3}$ & 3.11 & - & 251.2 & 50 & 124.1 & 30 & - & - & - & - & - & - \\
\hline Methylone- $d_{5}$ & 2.24 & - & 211.1 & 30 & 163.1 & 20 & - & - & - & - & - & - \\
\hline PMMA- $d_{3}$ & 2.70 & - & 183.1 & 40 & 121.1 & 20 & - & - & - & - & - & - \\
\hline$\alpha-P V P-d_{8}$ & 3.19 & - & 240.2 & 10 & 91.0 & 20 & - & - & - & - & - & - \\
\hline
\end{tabular}

a Illicit Drugs.

b Benzoylecgonine is the main metabolite of cocaine. 


\subsection{Quantitation}

For quantitation purposes, data (both UHPLC-MS/MS and $\mu \mathrm{LC}-\mathrm{MS} / \mathrm{MS}$ ) were acquired in selected reaction monitoring (SRM) mode. Three MS/MS transitions were acquired for each compound, using the most intense or selective one as the quantitation transition, and the other two transitions for confirmation purposes. All compounds were quantified using its corresponding ILIS as surrogate internal standard. If no ILIS was available, an analogue was chosen based on their ability to compensate matrix effect. Table 1 shows the MS/MS transitions selected, retention time (RT), mass spectrometric conditions and ILIS selected for each compound.

In the analysis of samples, the confirmation of positives was based on the accomplishment of $Q / q$ ratios, with deviation lower than $30 \%$ between samples and reference standards, and RT error less than $0.1 \mathrm{~min}[26]$.

\subsection{Method validation}

The method performance was evaluated in terms of linearity, matrix effect, robustness, accuracy, precision and limits of detection and quantitation.

Calibration curves were freshly prepared prior to each analysis. Linearity was evaluated by analyzing standard solutions in solvent at eight concentration levels ranging from 0.1 to $50 \mu \mathrm{g} \mathrm{L}^{-1}$ (equivalent to 4-2000 $\mathrm{ng} \mathrm{L}^{-1}$ in WW). Satisfactory linearity using weighted $(1 / X)$ least squares regression was considered when the correlation coefficient $(\mathrm{R})$ was greater than 0.99 .

Matrix effect was evaluated by analyzing matrix-matched standards at $25 \mu \mathrm{gL}^{-1}$ and comparing with standards in solvent. Robustness, precision and accuracy analysis were evaluated by spiking WW at 100 and $1000 \mathrm{ng} \mathrm{L}^{-1}$. Recovery was considered as acceptable when it was between 70 and $120 \%$, with RSD within $\pm 20 \%$.

Limits of quantification (LOQ) were calculated for a signal-tonoise $(\mathrm{S} / \mathrm{N})$ ratio of 10 using the quantitation transition in samples spiked at the lowest validation level. Additionally, at least one confirmation transition needed to show $\mathrm{S} / \mathrm{N}$ ratio $\geq 3$. Instrumental limits of detection (ILD) were set up for an $\mathrm{S} / \mathrm{N}$ ratio $=3$ in standards in solvent at the lowest concentration of the calibration line.

\subsection{Collection of samples}

Higher consumption of NPS and ID is often expected on weekends rather than weekdays when people unwind from weekday's routine. Therefore, for monitoring the consumption of these type of substances through the analysis of WW, it was considered more suitable to collect WW samples on weekends [6].

24 h composite samples were taken from 8 different WWTPs by taking an aliquot of the influent stream every $15 \mathrm{~min}$. Immediately, samples were frozen $\left(-20^{\circ} \mathrm{C}\right)$ and delivered to the laboratory. For each WWTP, a weekend-pooled sample was obtained by mixing Friday, Saturday and Sunday samples (1:1:1). Samples were analyzed by the fully validated UHPLC-MS/MS method.

\section{Results and discussion}

\subsection{Exploring the capabilities of $\mu L C-M S / M S$}

The potential application of $\mu \mathrm{LC}$ for the determination of ID and NPS in WW was tested and compared to conventional UHPLC in terms of chromatographic separation, injection volume, sensitivity and in-matrix reproducibility.

\subsubsection{Chromatographic separation}

Chromatographic separation was initially assessed with $\mathrm{H}_{2} \mathrm{O}$ :MeOH mobile phases resulting in sparse peak shapes. Consequently, $\mathrm{HCOOH}$ was added to both mobile phases in order to enhance the formation of the protonated molecule and, therefore, to improve compound sensitivity. The best conditions were found adding $0.01 \% \mathrm{HCOOH}$ to both $\mathrm{H}_{2} \mathrm{O}$ and $\mathrm{MeOH}$. Moreover, the addition of ammonium acetate at different concentrations was also considered. It was found that $5 \mathrm{mM}$ of $\mathrm{NH}_{4} \mathrm{Ac}$ in aqueous mobile phase improved the peak shape for some compounds. However, it was thought to be causing over pressure in the $\mu$ LC fluidics because of poor solubility in methanol (roughly 20 times less than in pure $\mathrm{H}_{2} \mathrm{O}$ ) [27]. This behavior is not an issue of concern in conventional UHPLC systems because of the higher fluidics dimensions, but it becomes important when going down to micro-flow systems with capillary tubes. Finally, its utilization was avoided and only $\mathrm{HCOOH}$ was added to mobile phases.

The gradient selected for the appropriate elution of all compounds included in the study consisted on a first slow and steady increase in the percentage of organic phase (from 30\% to $60 \%$ in $2 \mathrm{~min}$ ) permitting good separation, especially for the cathinones and the amphetamine-like compounds. This was followed by an abrupt increase up to $90 \%$ of mobile phase B in $0.1 \mathrm{~min}$. The latter favors the elution of less polar compounds of the matrix and results in a 5.50 min chromatographic run time.

For the $\mu \mathrm{LC}$ system, different flow rates, ranging from 0.5 to $3 \mu \mathrm{Lmin}^{-1}$, were tested to evaluate the sensitivity The reduction of flow rate resulted in poor peak shape and lower sensitivity for highly polar and small compounds such as cathinones and amphetamines. In addition, run time increased significantly because of dead-volumes playing an important role in micro-fluidic systems. No flow rates higher than $3 \mu \mathrm{Lmin}^{-1}$ were tested since system pressure was close to the highest operating limit. Finally, $3 \mu \mathrm{L} \mathrm{min}^{-1}$ was selected.

The low flow rates applied in $\mu$ LC result in increased sensitivity due to the higher ionization efficiency compared to conventional flow rates used in UHPLC. This was demonstrated by comparing the normalized peak areas (Table 2), where the increasing factor in sensitivity was between 6 and 53.1 times for the substances investigated. The hundred-fold reduction in flow rate is not only important for the sensitivity point of view. It also leads to a notable decrease in the consumption of organic solvents moving $\mu \mathrm{LC}$ systems towards a more green analytical chemistry.

\subsubsection{Injection volume and injection solvent composition}

Injection volumes of $0.1,0.2$ and $0.5 \mu \mathrm{L}$ in partial loop mode and $1 \mu \mathrm{L}$ in full loop mode were tested in the $\mu \mathrm{LC}$ system. For appropriate response comparison, peak areas were normalized with the sample volume injected in the system. Fig. S2 shows the peak area:injected volume ratio for mephedrone, methoxetamine, $\alpha$ PVP and dipentylone, as illustrative examples of the general trend observed for all compounds. The best peak area:injected volume ratio was found at an injection volume of $1 \mu \mathrm{L}$ for all compounds.

Injection volume and sample extract composition are two strategic instrumental parameters to optimize during method development. Depending on the injection mode (full or partial loop), sample composition becomes of paramount importance for compound retention in the head of the column especially in microfluidic systems. When working in partial loop mode, the selected amount of sample is loaded and the rest of the loop is filled with weak washing solvent $\left(\mathrm{H}_{2} \mathrm{O}\right)$ (see Fig. S3 in Supporting Information). Therefore, if the extract and weak solvent compositions are not similar, diffusion of matrix extract in the aqueous phase could occur causing poor retention of compounds, and spreading peaks throughout the chromatogram. 
Table 2

Comparison of UHPLC-MS/MS and $\mu$ LC-MS/MS sensitivity (normalized response) and method performance (absolute area) for ID and NPS.

\begin{tabular}{|c|c|c|c|c|c|c|}
\hline \multirow[b]{2}{*}{ Compound } & \multicolumn{3}{|c|}{ Normalized response (peak area per 10 pg of substance injected) } & \multicolumn{3}{|l|}{ Absolute area } \\
\hline & $\begin{array}{l}\text { UHPLC (peak } \\
\text { area/10 pg) }\end{array}$ & $\begin{array}{l}\mu \mathrm{LC} \text { (peak } \\
\text { area/10 pg) }\end{array}$ & $\begin{array}{l}\text { Sensitivity improvement } \\
\text { factor ( } \mu \mathrm{LC} / \mathrm{UHPLC})\end{array}$ & $\begin{array}{l}\text { UHPLC (peak } \\
\text { area) }\end{array}$ & $\mu \mathrm{LC}$ (peak area) & $\begin{array}{l}\text { Sensitivity improvement } \\
\text { factor ( } \mu \text { LC/UHPLC) }\end{array}$ \\
\hline Amphetamine ${ }^{a}$ & 4111 & 218444 & 53.1 & 12333 & 218444 & 17.7 \\
\hline Benzoylecgonine $\mathrm{b}^{\mathrm{b}}$ & 289298 & 2002463 & 6.9 & 867894 & 2002463 & 2.3 \\
\hline Butylone & 171688 & 1409698 & 8.2 & 515064 & 1409698 & 2.7 \\
\hline Cocaine $^{\mathrm{a}}$ & 432300 & 3363345 & 7.8 & 1296900 & 3363345 & 2.6 \\
\hline Dimethylone & 117516 & 816537 & 6.9 & 352548 & 816537 & 2.3 \\
\hline Dipentylone & 180165 & 1613366 & 9.0 & 540495 & 1613366 & 3.0 \\
\hline Ketamine & 121797 & 1197573 & 9.8 & 365391 & 1197573 & 3.3 \\
\hline MDMA $^{\mathrm{a}}$ & 256935 & 2602112 & 10.1 & 770805 & 2602112 & 3.4 \\
\hline MDPV & 171838 & 1031096 & 6.0 & 515514 & 1031096 & 2.0 \\
\hline Mephedrone & 353980 & 3565801 & 10.1 & 1061940 & 3565801 & 3.4 \\
\hline Methamphetamine ${ }^{a}$ & 26482 & 866645 & 32.7 & 79446 & 866645 & 10.9 \\
\hline Methedrone & 190383 & 3103025 & 16.3 & 571149 & 3103025 & 5.4 \\
\hline Methoxetamine & 201885 & 1550649 & 7.7 & 605655 & 1550649 & 2.6 \\
\hline Methylone & 95853 & 578751 & 6.0 & 287559 & 578751 & 2.0 \\
\hline $\mathrm{N}$-ethcathinone & 10101 & 354736 & 35.1 & 30303 & 354736 & 11.7 \\
\hline PMMA & 165882 & 1815450 & 10.9 & 497646 & 1815450 & 3.6 \\
\hline$\alpha-P V P$ & 54328 & 562469 & 10.4 & 162984 & 562469 & 3.5 \\
\hline 3,4,-DiMeO- $\alpha$-PVP & 124625 & 937913 & 7.5 & 373875 & 937913 & 2.5 \\
\hline $4-C-\alpha-P P P$ & 107722 & 1103581 & 10.2 & 323166 & 1103581 & 3.4 \\
\hline 4-FMC & 117408 & 994430 & 8.5 & 352224 & 994430 & 2.8 \\
\hline 4-MEC & 44783 & 698796 & 15.6 & 134349 & 698796 & 5.2 \\
\hline 4-МеРPР & 154231 & 1596327 & 10.4 & 462693 & 1596327 & 3.5 \\
\hline
\end{tabular}

a Illicit Drugs.

b Benzoylecgonine is the main metabolite of cocaine.

Sample extract composition also becomes an issue of concern because of the small column volume of the iKey device, which is nearly $0.35 \mu \mathrm{L}$ and translates into a maximum suggested injection volume of $0.03 \mu \mathrm{L}$ [28]. Working with an injection volume of $1 \mu \mathrm{L}$ means overloading the chromatographic column with approximately 3,333\%, which significantly compromises chromatographic resolution, especially for early eluting peaks. Thus the injection solution strength should be as low as possible (ideally, non-organic content). In this way, although the injected amount of sample is larger than the loading capacity, compounds are retained in the head of column and not eluted with injection solvent.

In conventional UHPLC systems, few microliters of sample are typically injected as well. However, the loading capacity of the chromatographic columns is significantly larger than $\mu \mathrm{LC}$ columns and, therefore, injection volume does not exceed the maximum recommended. Hence, higher organic compositions and higher injection volumes could be used without compromising chromatographic separation.

\subsubsection{Sensitivity comparison of $\mu L C-M S / M S$ and UHPLC-MS/MS}

A comprehensive comparison in terms of sensitivity was made between $\mu$ LC-MS/MS and conventional UHPLC-MS/MS systems. For this purpose, a standard solution containing $10 \mu \mathrm{g} \mathrm{L}^{-1}$ of all compounds was injected in both instruments at the injection volumes previously selected, i.e. $1 \mu \mathrm{L}$ and $3 \mu \mathrm{L}$, respectively. Fig. 1 shows the chromatograms corresponding to the $Q$ transition of methoxetamine, $\alpha$-PVP and PMMA in $\mu$ LC-MS/MS and UHPLC$\mathrm{MS} / \mathrm{MS}$ as illustrative examples of the sensitivity differences.

Both, sensitivity enhancement provided by the technique and absolute method performance, have been evaluated. Table 2 , shows a comparison of the peak area normalized per $10 \mathrm{pg}$ of substance injected for both techniques as well as the ratio between normalized peak areas. It can be seen that the utilization of micro-flow techniques is more beneficial for the more polar compounds, such as amphetamine, N-ethcathinone and methamphetamine, which showed an increase factor in sensitivity of 53.1, 35.1 and 32.7, respectively. For less polar compounds, such as methylone, MDPV, benzoylecgonine and dimethylone, sensitivity in $\mu$ LC increased approximately 6 times. The average increasing factor in sensitivity from UHPLC to $\mu$ LC systems was approximately 14 .

The higher volume injected into a UHPLC system may be, however, an advantage. The overall method performance between $\mu \mathrm{LC}$ and UHPLC can be compared if the absolute peak areas are brought into comparison. Even though the optimized injection volume used in UHPLC was 3 times higher than in $\mu \mathrm{LC}(3 \mu \mathrm{L} v s 1 \mu \mathrm{L})$, the overall sensitivity achieved with $\mu \mathrm{LC}$ methodology was still on average 4.5 times higher. Yet, it should be considered that the volume that can be injected in a UHPLC system is more flexible, and might be, in principle, increased to improve sensitivity. In order to reach comparable levels of overall method sensitivity with $\mu \mathrm{LC}, 14 \mu \mathrm{L}$ of sample extract would be needed in UHPLC. However, an increase in injection volume may not always be beneficial because more matrix is also injected and can result in considerable issues related to matrix effects.

The increase in sensitivity associated to micro-flow techniques is highly valuable especially for compounds, such as NPS and some ID, that are present at very low concentration levels in water. Thus, $\mu \mathrm{LC}-\mathrm{MS} / \mathrm{MS}$ presents, in principle, strong potential for the monitoring of NPS consumption by means of WW analysis.

\subsubsection{In-matrix reproducibility}

$\mu \mathrm{LC}-\mathrm{MS} / \mathrm{MS}$ systems have been reported to be less matrix interfered than conventional UHPLC-MS/MS systems [29]. Due to its intrinsic low flow rate, the ionization efficiency is higher than in conventional ESI sources resulting in less ion suppression. However, this low matrix interference is referred solely to the ion suppression that can potentially occur in the ionization process. On the contrary, the effect of matrix was more severe on the chromatographic retention for the compounds included in this study.

Two randomly selected WW samples were spiked at $10 \mu \mathrm{g} \mathrm{L}^{-1}$ to assess the robustness of the chromatographic separation as well as the effect on the matrix. Fig. 2 shows the chromatograms ( $Q$ transition) for the WW samples spiked with PMMA, methoxetamine, ketamine, and methedrone. As shown, strong deviations in RT, 


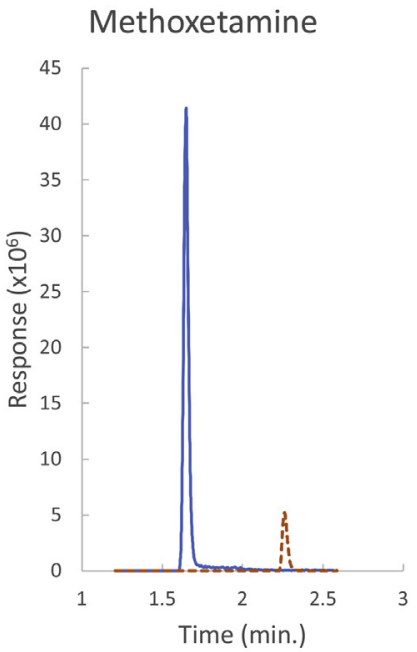

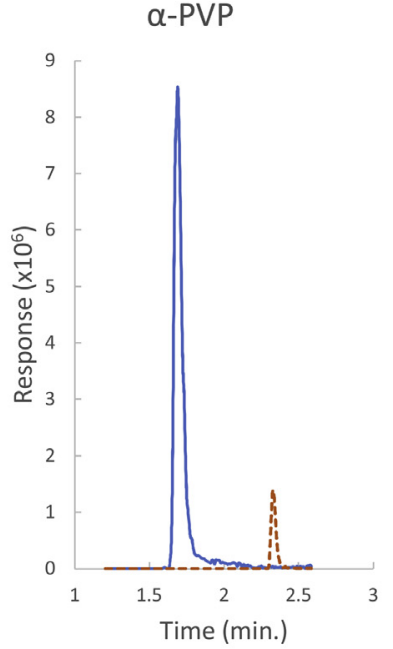

$\mu \mathrm{LC}-\mathrm{MS} / \mathrm{MS}$ system
PMMA

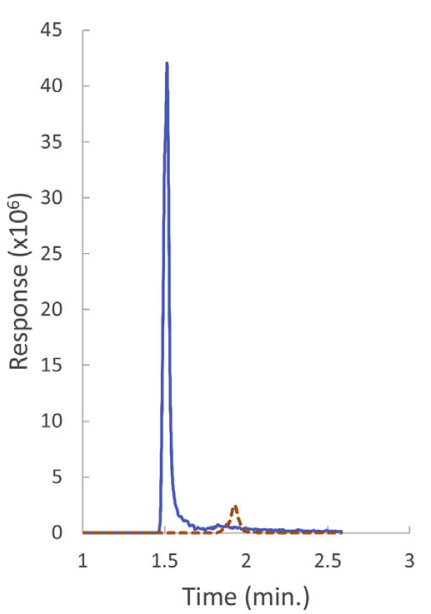

UHPLC-MS/MS system

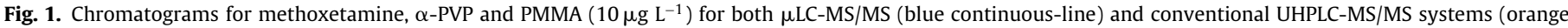
dashed-line). (For interpretation of the references to colour in this figure legend, the reader is referred to the web version of this article).

PMMA

$(Q, 180.1>149.0)$

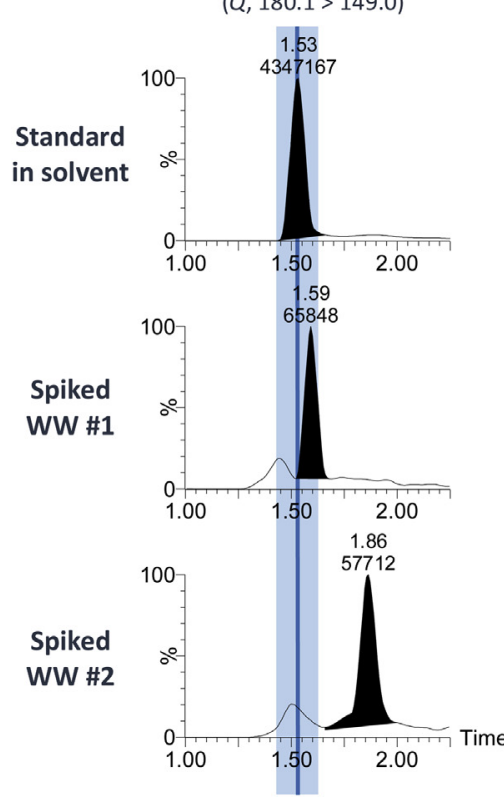

Methoxetamine

$(Q, 248.2>121.1)$
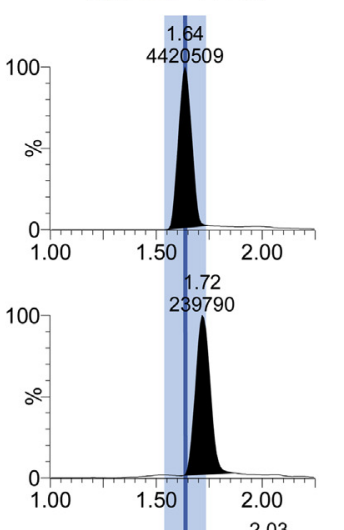

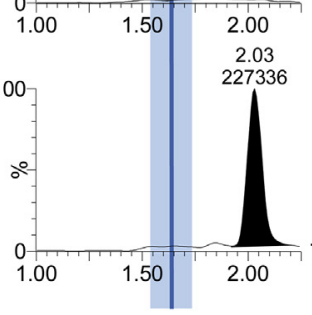

Ketamine

$(Q, 238.2>125.0)$
Methedrone

$(Q, 194.1>161.3)$
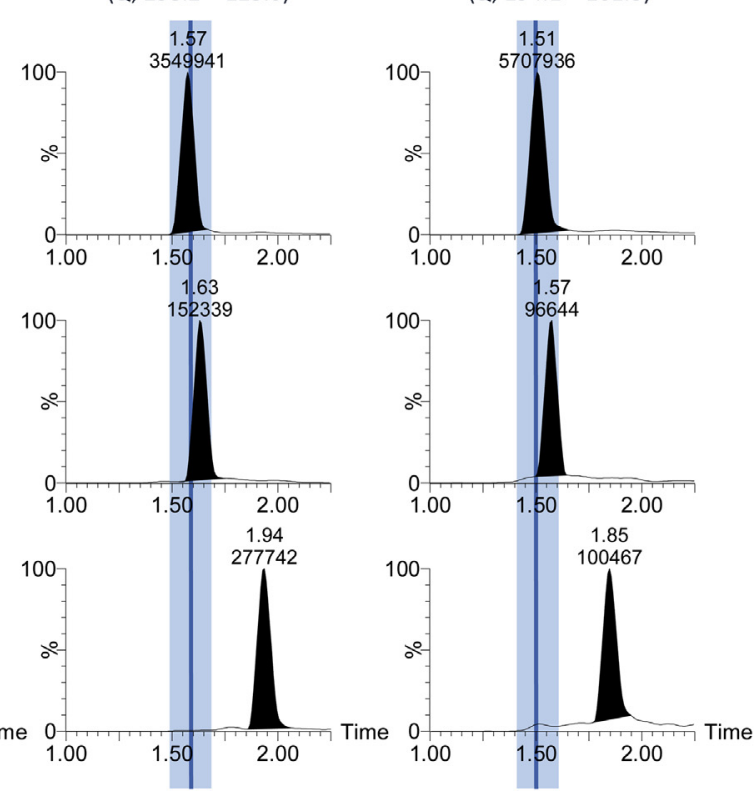

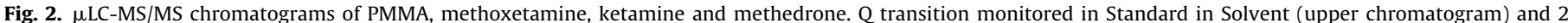

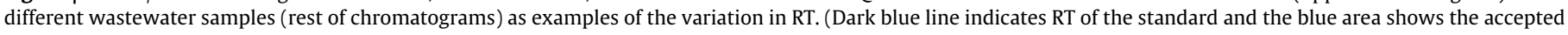
deviation of RT in sample). (For interpretation of the references to colour in this figure legend, the reader is referred to the web version of this article).

up to roughly $0.4 \mathrm{~min}$, were observed. The vast majority of the compounds showed similar behavior in the spiked samples. The variability in RT illustrates how matrix composition affects analyte retention in the chromatographic column. Again, injection volume plays a key role in $\mu$ LC-MS/MS since a large overloading of the column could result in an altered retention capacity [28], which usually is not an issue of concern in UHPLC.

Since reproducibility of RT is of great relevance in all type of analysis, particularly in complex matrix samples, such as WW, where the confirmation of identity of the compounds may become problematic, the $\mu \mathrm{LC}-\mathrm{MS} / \mathrm{MS}$ methodology tested in this work was found not robust enough for the determination of NPS and ID in WW. Consequently, validation of the method and subsequent analysis of samples was only performed by UHPLC-MS/MS.

\subsection{Method validation}

The poor RT reproducibility of $\mu \mathrm{LC}-\mathrm{MS} / \mathrm{MS}$, leads us to select UHPLC-MS/MS for subsequent method validation and real-world WW sample analysis. As several analytes were present in the "blank" samples used for validation, all the analytical data presented herein are blank-corrected.

Table 3 shows a summary of linearity, recovery, ILD and LOQ for the NPS and ID investigated. Good linearity within $0.1-50 \mu \mathrm{g} \mathrm{L}^{-1}$ with correlation coefficients $(\mathrm{R})$ greater than 0.99 was observed in all cases. LOQs ranged from 3 (cocaine, benzoylecgonine, MDMA) to 70 (amphetamine) $\mathrm{ng} \mathrm{L}^{-1}$ in raw WW, and were similar to those reported in the literature $[5,6,30]$. Precision and accuracy $(n=5)$ were evaluated by spiking 'blank' WW samples at two concen- 
Table 3

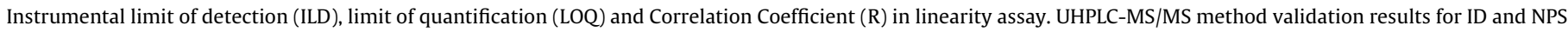
in WW.

\begin{tabular}{|c|c|c|c|c|c|}
\hline \multirow{2}{*}{ Compound } & \multicolumn{2}{|c|}{ Recovery (RSD\%) } & \multirow{2}{*}{$\operatorname{ILD}(\mathrm{fg})$} & \multirow{2}{*}{$\begin{array}{l}\mathrm{LOQ}\left(\mathrm{ng} \mathrm{L}^{-1} \text { in }\right. \\
\mathrm{WW})\end{array}$} & \multirow{2}{*}{$\begin{array}{l}\text { Correlation } \\
\text { coefficient (R) }\end{array}$} \\
\hline & $100 \mathrm{ng} \mathrm{L}^{-1}$ & $1000 \mathrm{ng} \mathrm{L}^{-1}$ & & & \\
\hline Amphetamine $^{\mathrm{a}}$ & $75(16)$ & $117(6)$ & 133 & 70 & 0.9936 \\
\hline Benzoylecgonine $^{\mathrm{b}}$ & $-c$ & $90(3)$ & 13 & 3 & 0.9982 \\
\hline Butylone & $96(5)$ & $95(3)$ & 132 & 6 & 0.9994 \\
\hline Cocaine $^{\mathrm{a}}$ & $120(7)$ & $114(2)$ & 16 & 3 & 0.9963 \\
\hline Dimethylone & $100(3)$ & $97(5)$ & 129 & 20 & 0.9987 \\
\hline Dipentylone & $105(8)$ & $107(6)$ & 68 & 6 & 0.9986 \\
\hline Ketamine & $102(8)$ & $92(3)$ & 80 & 4 & 0.9990 \\
\hline MDMA $^{\mathrm{a}}$ & $93(1)$ & $100(2)$ & 32 & 3 & 0.9994 \\
\hline MDPV & $88(17)$ & $96(7)$ & 88 & 21 & 0.9990 \\
\hline Mephedrone & $109(5)$ & $112(3)$ & 21 & 5 & 0.9909 \\
\hline Methamphetamine ${ }^{a}$ & $114(14)$ & $119(4)$ & 51 & 21 & 0.9988 \\
\hline Methedrone & $92(6)$ & $94(5)$ & 42 & 6 & 0.9977 \\
\hline Methoxetamine & $107(9)$ & $105(5)$ & 53 & 5 & 0.9996 \\
\hline Methylone & $104(3)$ & $103(5)$ & 57 & 4 & 0.9967 \\
\hline N-ethcathinone & $76(14)$ & $88(7)$ & 42 & 41 & 0.9978 \\
\hline PMMA & $111(6)$ & $99(5)$ & 19 & 10 & 0.9927 \\
\hline$\alpha-P V P$ & $101(15)$ & $95(11)$ & 103 & 43 & 0.9988 \\
\hline 3,4-DiMeO- $\alpha$-PVP & $103(4)$ & $99(7)$ & 142 & 9 & 0.9954 \\
\hline 4-chloro- $\alpha$-PPP & $85(16)$ & $84(8)$ & 36 & 17 & 0.9957 \\
\hline 4-FMC & $86(11)$ & $92(9)$ & 31 & 30 & 0.9971 \\
\hline 4-MEC & $88(5)$ & $96(5)$ & 49 & 5 & 0.9956 \\
\hline 4-МеРРР & $85(5)$ & $93(5)$ & 110 & 18 & 0.9970 \\
\hline
\end{tabular}

a Illicit Drugs.

b Benzoylecgonine is the main metabolite of cocaine.

c Recovery of Benzoylecgonine in lowest spiked level not calculated because of the high concentration of Blank sample.

tration levels (100 and $1000 \mathrm{ng} \mathrm{L}^{-1}$ ). The results obtained for all compounds were satisfactory at both spiking levels, with recoveries between $75-114 \%$ at the lowest level and $84-119 \%$ at the highest level. Precision (RSD) was in the range 1 to $16 \%$ at the lowest spiked level and $2-11 \%$ at the highest spiked level. It is noteworthy that recovery for benzoylecgonine was not calculated at the lowest level due to the high concentration of this chemical in the "blank" WW used for validation purposes. Matrix effects were evaluated using matrix-matched standards. The matrix extracted with SPE resulted in different rates of ion suppression, which were corrected by using appropriate ILIS.

\subsection{Sample analysis}

Pooled weekend WW samples were analyzed by means of the validated UHPLC-MS/MS methodology described above.

All the monitored ID were confirmed and quantified in any of the samples analyzed, with cocaine (and its main metabolite benzoylecgonine) and MDMA being found in all the analyzed samples (Table 4). Amphetamine was confirmed and quantified in all samples except one where it was found below the LOQ level. Methamphetamine showed a great variability in concentration levels, being below LOQ in half of the samples. Regarding NPS, ketamine and dipentylone were confirmed and quantified in some WW. It is noteworthy to highlight the presence of ketamine in all samples above LOQ level, suggesting an established consumption in the assessed communities. The same trend for ketamine was observed in several Italian cities from 2008 to 2014. Despite ketamine being an emerging NPS at that moment, an increase on its consumption was detected in all cities included in the study [31]. The EMCDDA defines NPS as 'newly misused' substances; therefore, the persevering consumption of ketamine makes this substance not strictly fitting this criterion. However, in this study ketamine has still been considered as NPS because of its novelty in comparison with the traditional ID (cocaine, amphetamine, etc.). Butylone, mephedrone, methedrone and methylone were also found in three samples.
Confirmation of compound identity required the accomplishment of RT (deviation $\leq 0.1 \mathrm{~min}$ ) and $Q / q$ ratios (deviation $\leq 30 \%$ in at least one out of the two confirmatory transitions) in comparison with the reference standard. Fig. 3a shows an example of MDMA confirmation (full agreement with reference standard). The problematic identification of mephedrone in one of the samples is also illustrated in this figure (Fig. 3b). The RT in sample agreed with the quality control (spiked "blank" sample), but only one confirmatory transition was observed $\left(\mathrm{Q} / \mathrm{q}_{1}\right)$, because the third transition $\left(\mathrm{Q} / \mathrm{q}_{2}\right)$ available had very unfavorable ion ratio (see Table 1$)$ and could not be detected. Unfortunately, the deviation of $Q / q_{1}$ ratio was above $30 \%$, and mephedrone could, therefore, not be confirmed. Additional analysis (e.g. modifying chromatographic conditions, additional clean-up, etc.) would be required for confirmation of that potential positive.

Despite some NPS have been identified/quantified (butylone, dipentylone, ketamine, mephedrone, methedrone and methylone), the most abundant drug found in WW was cocaine (and its main metabolite benzoylecgonine) followed by amphetamine, suggesting the consumers preference for known ID rather than the NPS investigated. Among the NPS detected, some compounds have been also found by other studies. Thus, Bade et al. reported the presence of mephedrone, methylone and MDPV (not detected in this study) in WW from different European cities in 2017 [5]. Senta et al. found methedrone, methylone, mephedrone and ketamine in Croatia [32]. In addition, butylone, mephedrone, methylone, $\alpha$-PVP and MDPV (among other compounds not included in this study) were also reported by Fontanals et al. in the east coast of Spain [33]. The fact that MDPV and $\alpha$-PVP were not found in the wastewaters analyzed in this work might be associated to the ever changing NPS market, which is constantly evolving to look for new substances.

It is worth to notice that dipentylone has been found in WW for the first time. Further studies in the forthcoming years will be required to assess whether dipentylone has appeared in the NPS market to become a largely consumed substance or its presence in WW is due to an acute peak of consumption. The results obtained in this work reveal that WW analysis has potential for the assessment 
Table 4

Concentration (in $\mathrm{n} \mathrm{L}^{-1}$ ) of five ID and metabolites and six NPS found in influent WW from eight WWTPs.

\begin{tabular}{|c|c|c|c|c|c|c|c|c|c|}
\hline & \multirow[b]{3}{*}{ Compound } & \multicolumn{8}{|c|}{ Location WWTP } \\
\hline & & 1 & 2 & 3 & 4 & 5 & 6 & 7 & 8 \\
\hline & & \multicolumn{8}{|c|}{ Concentration in raw wastewater ${ }^{\mathrm{a}}\left(\mathrm{ng} \mathrm{L}^{-1}\right)$} \\
\hline \multirow{5}{*}{ ID } & Amphetamine & 716 & 7565 & 194 & 307 & 1527 & 382 & 1564 & $<$ LOQ \\
\hline & Benzoylecgonine $^{\mathrm{b}}$ & 4594 & 10558 & 3416 & 2724 & 5783 & 5268 & 2232 & 297 \\
\hline & Cocaine & 1165 & 2316 & 585 & 809 & 1177 & 961 & 206 & 31 \\
\hline & MDMA & 250 & 110 & 28 & 73 & 316 & 150 & 144 & 216 \\
\hline & Methamphetamine & 159 & $<\mathrm{LOQ}$ & 34 & $<\mathrm{LOQ}$ & 296 & $<$ LOQ & $<$ LOQ & 406 \\
\hline \multirow{6}{*}{ NPS } & Butylone & - & - & - & - & - & - & $d$ & - \\
\hline & Dipentylone & - & - & 6.4 & - & - & - & - & - \\
\hline & Ketamine & 38 & 33 & 8.0 & 57 & 79 & 23 & 22 & 9.6 \\
\hline & Mephedrone & $d$ & - & - & - & - & - & - & - \\
\hline & Methedrone & - & $d$ & - & - & - & - & - & - \\
\hline & Methylone & - & - & - & - & - & - & $d$ & - \\
\hline
\end{tabular}

a <LOQ: Below limit of quantification; $d$ : Compound detected but not confirmed because of deviations in $Q / q$ ratios; -: Not Detected.

b Main metabolite of Cocaine.

(a) MDMA confirmation
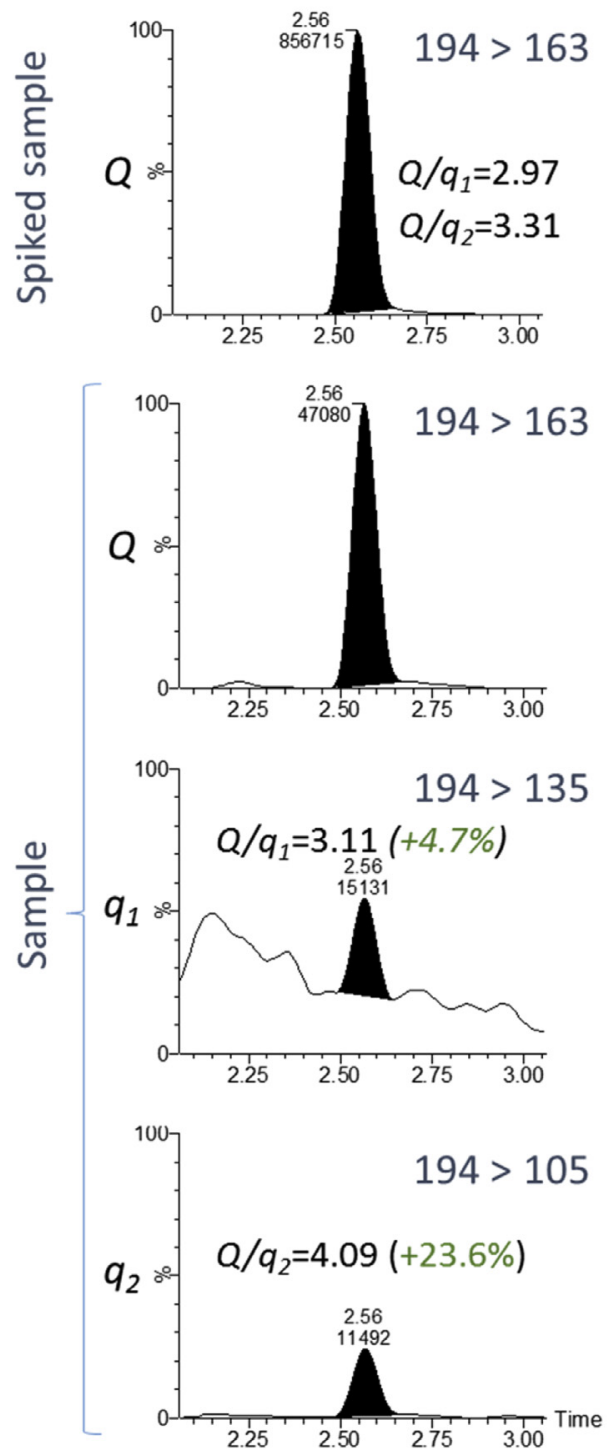

(b) Mephedrone detection
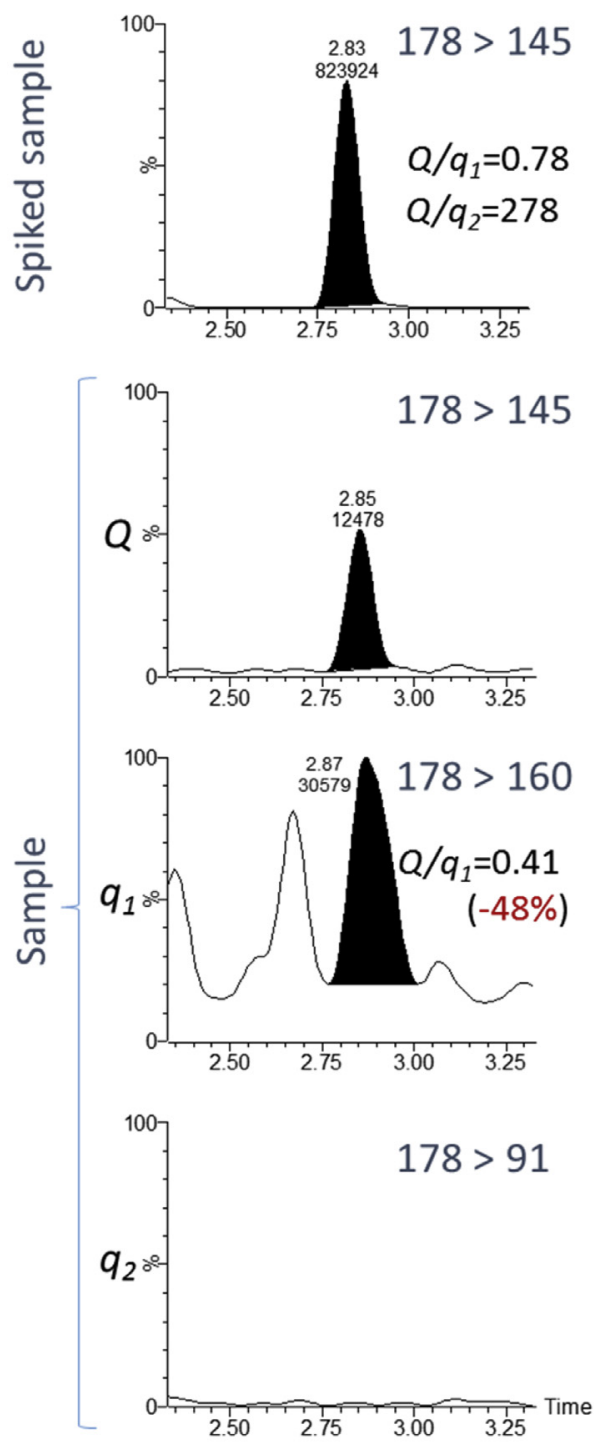

Fig. 3. Selected examples of UHPLC-MS/MS analysis of wastewater samples. (a) MDMA confirmation in wastewater. (b) Mephedrone detection in wastewater.

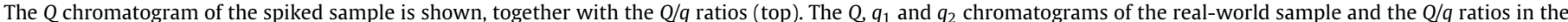

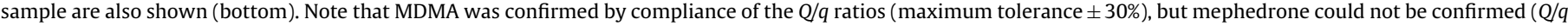
deviation $-48 \%)$. 
of NPS consumption in a community, as up to 6 NPS have been found, one of them for the first time.

\subsection{Strengths and limitations of micro-LC for wastewater-based epidemiology applications}

Recently developed integrated $\mu$ LC-ESI chip interfaces have revolutionized micro-LC technique. The older capillary chromatography instruments were highly user-dependent in terms of assembling pieces; however, the new integrated devices provide similar instrumental robustness as conventional UHPLC systems. This strongly facilitates their utilization, enabling analytical applications with enhanced sensitivity [16].

Moving from UHPLC to micro-LC separation require some strategic method rearrangements since sample composition and injection volume play an important role in micro-LC. Furthermore, the quality of solvents and mobile phase additives solubility are crucial in micro-LC separations. For the determination of NPS and ID in WW, small arrangements such as working with low percentage of organic solvent in the sample extract and in full-loop injection mode led to a notable increase in sensitivity using only a few millilitres of WW sample for analysis.

Wastewater is a highly complex matrix for the analysis of low concentrated substances such as ID and NPS. Besides, WW composition can vary considerably between locations, or even between days within the same location. In this work, the tested $\mu$ LC-MS methodology was greatly affected by the sample matrix resulting in bad RT reproducibility, which however did not affect to conventional UHPLC-MS/MS. A major issue is considerable sensitivity improvement observed for $\mu \mathrm{LC}-\mathrm{MS} / \mathrm{MS}$ in comparison to conventional UHPLC-MS/MS with up to 53-increase fold (average increase for all compounds, 14), especially for early-eluting compounds, such as cathinones and amphetamines. The overall method performance using $\mu \mathrm{LC}$-MS/MS also improved, up to 17.7- increase fold (4.5 times on average).

The observed increase in sensitivity makes micro-fluidic techniques an attractive approach for WBE applications in the near future. With low prevalence of consumption, high variability of choice for consumers and low doses for most NPS, an enhanced sensitivity might be the difference between detection or not detection in WW. Further investigation to get better reproducibility across samples (e.g. modifications in sample treatment) will allow to monitor controlled and non-controlled substances reaching lower detection limits than those provided by UHPLC-MS methodologies. Manufacturers progresses, such as the development of column chemistries more inert to the matrix with higher injection volume capacities, would facilitate the application of this technique as well. The high cost of the iKey columns and of the high-quality solvents required in $\mu \mathrm{LC}$ are also relevant issues that need to be considered. A major point is that $\mu \mathrm{LC}$ techniques represent a step forward into a greener analytical chemistry thanks to the less amount of sample and organic solvents needed.

\section{Conclusions}

A simultaneous sensitive analytical methodology, based on SPE and UHPLC-MS/MS, has been developed for quantitative determination of 22 compounds, including ID, NPS and some of their main metabolites, in wastewater samples. The sample throughput has been improved in comparison with other reported methodologies by reducing the amount of sample loaded in the cartridge. The small sample volume required for analysis $(5 \mathrm{~mL})$ notably facilitates sample collection and shipping in large sampling campaigns. The methodology has been successfully applied to pooled weekend WW samples in which cocaine, amphetamine, and MDMA were the most abundant drugs. Six NPS (ketamine, dipentylone, butylone, mephedrone, methedrone and methylone) were also found, with ketamine being present in all analyzed samples.

Moreover, the potential application of $\mu \mathrm{LC}-\mathrm{MS} / \mathrm{MS}$ in WBE studies has been evaluated and thoroughly compared to UHPLC-MS/MS. The adaptation of UHPLC-MS/MS methodologies to $\mu$ LC-MS/MS require to carefully consider sample matrix composition and to optimize injection volume since these parameters playing a key role in the chromatographic separation. The matrix effect on compound chromatographic retention was found an issue of concern because of the lack of RT reproducibility. However, the substantial increase in sensitivity, the high throughput of samples because of the low analysis time and the steps forward to a greener analytical chemistry make $\mu$ LC-MS/MS a promising tool for future applications in wastewater-based epidemiology.

\section{Acknowledgements}

The authors of University Jaume I acknowledge the financial support of Generalitat Valenciana (Prometeo II 2014/023) and of the Spanish Ministry of Economy and Competitiveness (Project: CTQ2015-65603-P). All authors acknowledge the financial support by the European project NPS-Euronet (HOME/2014/JDRU/AG/DRUG/7086). Dr. Lubertus Bijlsma acknowledges NPS-Euronet (HOME/2014/JDRUG/AG/DRUG/7086), co-funded by the European Union, for his post-doctoral fellowship. Alberto Celma acknowledges the Ministry of Economy and Competitiveness of Spain for his predoctoral grant (BES-2016-076914). Noelia Salgueiro-González acknowledges Xunta de Galicia and Axencia Galega de Innonavión (GAIN) for her postdoctoral fellowship (Modalidade A, 2016). This publication reflects only the views of the authors, and the European Commission cannot be held responsible for any use which may be made of the information contained therein.

\section{Appendix A. Supplementary data}

Supplementary material related to this article can be found, in the online version, at doi:https://doi.org/10.1016/j.chroma.2019. 05.051 .

\section{References}

[1] European Monitoring Centre for Drugs and Drug Addiction, European Drug Report 2018: Trends and Developments, Publications Office of the European Union, Luxembourg, 2018, http://dx.doi.org/10.2810/88175.

[2] R.A.S. Couto, L.M. Gonçalves, F. Carvalho, J.A. Rodrigues, C.M.P. Rodrigues, M.B. Quinaz, The analytical challenge in the determination of cathinones, key-players in the worldwide phenomenon of novel psychoactive substances, Crit. Rev. Anal. Chem. 48 (2018) 372-390, http://dx.doi.org/10.1080/ 10408347.2018.1439724.

[3] E. Gracia-Lor, S. Castiglioni, R. Bade, F. Been, E. Castrignanò, A. Covaci, I. González-Mariño, E. Hapeshi, B. Kasprzyk-Hordern, J. Kinyua, F.Y. Lai, T. Letzel, L. Lopardo, M.R. Meyer, J. O’Brien, P. Ramin, N.I. Rousis, A. Rydevik, Y. Ryu, M.M. Santos, I. Senta, N.S. Thomaidis, S. Veloutsou, Z. Yang, E. Zuccato, L. Bijlsma, Measuring biomarkers in wastewater as a new source of epidemiological information: current state and future perspectives, Environ. Int. 99 (2017) 131-150, http://dx.doi.org/10.1016/j.envint.2016.12.016.

[4] F. Hernández, S. Castiglioni, A. Covaci, P. de Voogt, E. Emke, B. Kasprzyk-Hordern, C. Ort, M. Reid, J.V. Sancho, K.V. Thomas, A.L.N. van Nuijs, E. Zuccato, L. Bijlsma, Mass spectrometric strategies for the investigation of biomarkers of illicit drug use in wastewater, Mass Spectrom. Rev. 37 (2018) 258-280, http://dx.doi.org/10.1002/mas.21525.

[5] R. Bade, L. Bijlsma, J.V. Sancho, J.A. Baz-Lomba, S. Castiglioni, E. Castrignanò, A. Causanilles, E. Gracia-Lor, B. Kasprzyk-Hordern, J. Kinyua, A.K. McCall, A.L.N. van Nuijs, C. Ort, B.G. Plósz, P. Ramin, N.I. Rousis, Y. Ryu, K.V. Thomas, P. de Voogt, E. Zuccato, F. Hernández, Liquid chromatography-tandem mass spectrometry determination of synthetic cathinones and phenethylamines in influent wastewater of eight European cities, Chemosphere. 168 (2017) 1032-1041, http://dx.doi.org/10.1016/j.chemosphere.2016.10.107.

[6] I. González-Mariño, E. Gracia-Lor, N.I. Rousis, E. Castrignanò, K.V. Thomas, J.B. Quintana, B. Kasprzyk-Hordern, E. Zuccato, S. Castiglioni, Wastewater-based epidemiology to monitor synthetic cathinones use in different European 
countries, Environ. Sci. Technol. 50 (2016) 10089-10096, http://dx.doi.org/10. 1021/acs.est.6b02644.

[7] R. Bade, P. Stockham, B. Painter, A. Celma, L. Bijlsma, F. Hernandez, J.M. White, C. Gerber, Investigating the appearance of new psychoactive substances in South Australia using wastewater and gorensic data, Drug Test. Anal. 11 (2019) 250-256, http://dx.doi.org/10.1002/dta.2484.

[8] L. Bijlsma, R. Gil-Solsona, F. Hernández, J.V. Sancho, What about the herb? a new metabolomics approach for synthetic cannabinoid drug testing, Anal. Bioanal. Chem. 410 (2018) 5107-5112, http://dx.doi.org/10.1007/s00216018-1182-8.

[9] D. Fabregat-Safont, J.V. Sancho, F. Hernández, M. Ibáñez, Rapid tentative identification of synthetic cathinones in seized products taking advantage of the full capabilities of triple quadrupole analyzer, Forensic Toxicol. 37 (2019) 34-44, http://dx.doi.org/10.1007/s11419-018-0432-y.

[10] D. Pasin, A. Cawley, S. Bidny, S. Fu, Current applications of high-resolution mass spectrometry for the analysis of new psychoactive substances: a critical review, Anal. Bioanal. Chem. 409 (2017) 5821-5836, http://dx.doi.org/10. 1007/s00216-017-0441-4.

[11] M.R. Meyer, H.H. Maurer, LC coupled to low- and high-resolution mass spectrometry for new psychoactive substance screening in biological matrices - where do we stand today? Anal. Chim. Acta 927 (2016) 13-20, http://dx.doi.org/10.1016/j.aca.2016.04.046.

[12] A. Causanilles, J. Kinyua, C. Ruttkies, A.L.N. van Nuijs, E. Emke, A. Covaci, P. de Voogt, Qualitative screening for new psychoactive substances in wastewater collected during a city festival using liquid chromatography coupled to high-resolution mass spectrometry, Chemosphere 184 (2017) 1186-1193, http://dx.doi.org/10.1016/j.chemosphere.2017.06.101.

[13] I. González-Mariño, E. Gracia-Lor, R. Bagnati, C.P.B. Martins, E. Zuccato, S. Castiglioni, Screening new psychoactive substances in urban wastewater using high resolution mass spectrometry, Anal. Bioanal. Chem. 408 (2016) 4297-4309, http://dx.doi.org/10.1007/s00216-016-9521-0.

[14] J.A. Baz-Lomba, M.J. Reid, K.V. Thomas, Target and suspect screening of psychoactive substances in sewage-based samples by UHPLC-QTOF, Anal. Chim. Acta 914 (2016) 81-90, http://dx.doi.org/10.1016/j.aca.2016.01.056.

[15] J. Kinyua, A. Covaci, W. Maho, A.K. Mccall, H. Neels, A.L.N. van Nuijs, Sewage-based epidemiology in monitoring the use of new psychoactive substances: validation and application of an analytical method using LC-MS/MS, Drug Test. Anal. 7 (2015) 812-818, http://dx.doi.org/10.1002/dta. 1777.

[16] A.J. Kleinnijenhuis, M. Ingola, J.H. Toersche, Quantitative bottom up analysis of infliximab in serum using protein A purification and integrated $\mu$ LCelectrospray chip IonKey MS / MS technology, Bioanalysis 8 (2016) 891-904 http://dx.doi.org/10.4155/bio-2015-0015.

[17] A.M. King, I. Grant, P.D. Rainville, G. Isaac, M. Coen, I.D. Wilson, R.S. Plumb, Capillary ultra performance liquid chromatography-tandem mass spectrometry analysis of tienilic acid metabolites in urine following intravenous administration to the rat, J. Chromatogr. B Anal. Technol. Biomed. Life Sci. 1087-1088 (2018) 142-148, http://dx.doi.org/10.1016/j.jchromb. 2018.04.034.

[18] C. Fanali, L. Dugo, P. Dugo, L. Mondello, Capillary-liquid chromatography (CLC) and nano-LC in food analysis, TrAC - Trends Anal. Chem. 52 (2013) 226-238, http://dx.doi.org/10.1016/j.trac.2013.05.021.

[19] J.P. Murphy, J. Johnson, P.D. Rainville, Enhancing Mass Spectrometry sensitivity by reducing chromatographic flow rates with Ionkey/MS, Waters White Pap., 2014, pp. 2-6

[20] P. Aggarwal, K. Liu, S. Sharma, J.S. Lawson, H. Dennis Tolley, M.L. Lee, Flow rate dependent extra-column variance from injection in capillary liquid chromatography, J. Chromatogr. A 1380 (2015) 38-44, http://dx.doi.org/10. 1016/j.chroma.2014.12.017.

[21] Y. Ma, N. Tanaka, A. Vaniya, T. Kind, O. Fiehn, Ultrafast polyphenol metabolomics of red wines using MicroLC-MS/MS, J. Agric. Food Chem. 64 (2016) 505-512, http://dx.doi.org/10.1021/acs.jafc.5b04890.

[22] G.J. Dear, R. Plumb, I.J. Fraser, The rapid identification of drug metabolites using capillary liquid chromatography coupled to an ion trap mass spectrometer, Rapid Commun. Mass Spectrom. 13 (1999) 456-463, http://dx. doi.org/10.1002/(SICI)1097-0231(19990315)13:5<456::AID-RCM508>3.0. $\mathrm{CO} ; 2-\mathrm{T}$.

[23] J. Suraj, A. Kurpińska, M. Olkowicz, E. Niedzielska-Andres, M. Smolik, A Zakrzewska, A. Jasztal, B. Sitek, S. Chlopicki, M. Walczak, Development, validation and application of a micro-liquid chromatography-tandem mass spectrometry based method for simultaneous quantification of selected protein biomarkers of endothelial dysfunction in murine plasma, J. Pharm. Biomed. Anal. 149 (2018) 465-474, http://dx.doi.org/10.1016/j.jpba.2017.11. 023.

[24] R.S. Plumb, H. Warwick, D. Higton, G.J. Dear, D.N. Mallett, Determination of 4-hydroxytamoxifen in mouse plasma in the $\mathrm{pg} / \mathrm{mL}$ range by gradient capillary liquid chromatography/tandem mass spectrometry, Rapid Commun. Mass Spectrom. 15 (2001) 297-303, http://dx.doi.org/10.1002/rcm.225.

[25] K. Murtada, F. De Andrés, Á. Ríos, M. Zougagh, A simple poly (styrene-co-divinylbenzene)-coated glass blood spot method for monitoring of seven antidepressants using capillary liquid chromatography-mass spectrometry, Talanta 188 (2018) 772-778, http://dx.doi.org/10.1016/j. talanta.2018.06.059.

[26] Guidance Document on Analytical Quality Control and Method Validation Procedures for Pesticide Residue and Analysis in Food and Feed. SANTE/11813/2017, European Commission. Directorate General for Health and Food Safety, 2017.

[27] P. Patnaik, Handbook of Inorganic Chemicals, McGraw-Hill, New York, United States of America, 2003.

[28] J.L. Simeone, J.P. Murphy, J. Johnson, A Guide to Performing Method Development for Direct Injection Methods Using ionKey / MS in a Bioanalytical Laboratory : From Sample Preparation to LC-MS, White Pap. Waters, 2017, pp. 1-7, 720005979E.

[29] J.S. Johnson, P.D. Rainville, J.P. Murphy, Taking Advantage of Significant Reductions in Ion Suppression Using ionKey/MS Compared to Standard-flow LC/MS, Waters White Pap., 2014.

[30] L. Bijlsma, E. Beltrán, C. Boix, J.V. Sancho, F. Hernández, Improvements in analytical methodology for the determination of frequently consumed illicit drugs in urban wastewater, Anal. Bioanal. Chem. 406 (2014) 4261-4272, http://dx.doi.org/10.1007/s00216-014-7818-4.

[31] S. Castiglioni, A. Borsotti, I. Senta, E. Zuccato, Wastewater analysis to monitor spatial and temporal patterns of use of two synthetic recreational drugs, Ketamine and Mephedrone, in Italy, Environ. Sci. Technol. 49 (2015) 5563-5570, http://dx.doi.org/10.1021/es5060429.

[32] I. Senta, I. Krizman, M. Ahel, S. Terzic, Multiresidual analysis of emerging amphetamine-like psychoactive substances in wastewater and river water, J. Chromatogr. A 1425 (2015) 204-212, http://dx.doi.org/10.1016/j.chroma. 2015.11.043.

[33] N. Fontanals, R.M. Marcé, F. Borrull, Solid-phase extraction followed by liquid chromatography-high resolution mass spectrometry to determine synthetic cathinones in different types of environmental water samples, J. Chromatogr. A 1524 (2017) 66-73, http://dx.doi.org/10.1016/j.chroma.2017.10.002. 